\title{
Noradrenergic Activity in the Olfactory Bulb Is a Key Element for the Stability of Olfactory Memory
}

\author{
${ }^{\circledR}$ Christiane Linster, ${ }^{1}$ Maellie Midroit, ${ }^{2}$ Jeremy Forest, ${ }^{2}{ }^{\circledR}$ Yohann Thenaisie, ${ }^{2}$ Christina Cho, ${ }^{1}$ Marion Richard, ${ }^{2}$ \\ Anne Didier, ${ }^{2}$ and Nathalie Mandairon ${ }^{2}$ \\ ${ }^{1}$ Computational Physiology Laboratory, Department of Neurobiolgy and Behavior, Cornell University, Ithaca, New York 14850, and ${ }^{2}$ Institut \\ National de la Santé et de la Recherche Médicale U1028, CNRS UMR 5292, and Neuroplasticity and Neuropathology of Olfactory Perception Team, \\ Lyon Neuroscience Research Center, University of Lyon, F-69000 Lyon, France
}

Memory stability is essential for animal survival when environment and behavioral state change over short or long time spans. The stability of a memory can be expressed by its duration, its perseverance when conditions change as well as its specificity to the learned stimulus. Using optogenetic and pharmacological manipulations in male mice, we show that the presence of noradrenaline in the olfactory bulb during acquisition renders olfactory memories more stable. We show that while inhibition of noradrenaline transmission during an odor-reward acquisition has no acute effects, it alters perseverance, duration, and specificity of the memory. We use a computational approach to propose a proof of concept model showing that a single, simple network effect of noradrenaline on olfactory bulb dynamics can underlie these seemingly different behavioral effects. Our results show that acute changes in network dynamics can have long-term effects that extend beyond the network that was manipulated.

Key words: computational; memory; noradrenaline; olfactory; stability

\section{Significance Statement}

Olfaction guides the behavior of animals. For successful survival, animals have to remember previously learned information and at the same time be able to acquire new memories. We show here that noradrenaline in the olfactory bulb, the first cortical relay of the olfactory information, is important for creating stable and specific olfactory memories. Memory stability, as expressed in perseverance, duration and specificity of the memory, is enhanced when noradrenergic inputs to the olfactory bulb are unaltered. We show that, computationally, our diverse behavioral results can be ascribed to noradrenaline-driven changes in neural dynamics. These results shed light on how very temporary changes in neuromodulation can have a variety of long-lasting effects on neural processing and behavior.

\section{Introduction}

Stability to maintain skills and stimulus associations while adjusting to new circumstances is fundamental for animal behavior. Neural systems need to be both flexible to adapt rapidly to new information and stable to maintain learned behaviors to ensure survival. Neuromodulatory systems in particular are thought to have evolved to convey flexibility to neural systems by

\footnotetext{
Received July 9, 2020; revised Sep. 4, 2020; accepted 0ct. 13, 2020.

Author contributions: C.L., Y.T., M.R., A.D., and N.M. designed research; C.L., M.M., J.F., Y.T., and C.C. performed research; C.L. and N.M. analyzed data; C.L. wrote the paper.

This work was supported by the CNRS, Institut National de la Santé et de la Recherche Médicale, Lyon 1 University (N.M.) and by Collaborative Research in Computational Neuroscience (CRCNS) Grant DC008702 (C.L.). We thank K. Deisseroth for the gift of the halorhodopsin construct; C. Benetollo from the Neurogenetic and Optogenetic Platform of the CRNL for lentiviral production; and G. Froment, D. Nègre, and C. Costa from the lentivector production facility/SFR BioSciences de Lyon (UMS3444/US8).

The authors declare no competing financial interests.

Correspondence should be addressed to Christiane Linster at CL243@cornell.edu.

https://doi.org/10.1523/JNEUROSCI.1769-20.2020

Copyright $\odot 2020$ the authors
}

allowing them to process stimuli in very different manners depending on behavioral demands.

For example, acetylcholine may sharpen stimulus-evoked oscillations in neural networks to enhance attention to a stimulus on a momentary basis (Sarter et al., 2006; Parikh and Sarter, 2008), dopamine (DA) may increase plasticity when a stimulus is unexpected and in need of reinforcement (Gentry et al., 2019), or norepinephrine (NE) may increase the signal-to-noise ratio in specific networks during moments of stress to enhance recognition and processing of a stimulus (McBurney-Lin et al., 2019). $\mathrm{NE}$ has long been associated with olfactory learning (Devore and Linster, 2012; Linster and Escanilla, 2019) and has been shown to strongly modulate the processing of olfactory stimuli as early as in the olfactory bulb (OB). NE inputs to the OB change processing of low-amplitude odors, increases associative learning, and increases the signal-to-noise ratio (Doucette et al., 2007; Escanilla et al., 2010, 2012; Devore and Linster, 2012; Linster and Escanilla, 2019). We here show that in addition to these acute effects, temporary manipulations of bulbar NE modulate the 
long-term stability of olfactory memories beyond the timeframe of the manipulations. We measure the stability of a memory by its perseverance during contextual changes, its duration, and its specificity for the encoded stimulus. We use optogenetic inhibition of locus coeruleus (LC) fibers locally in the olfactory bulbs during acquisition of an odor-reward association to temporarily decrease NE activity. Mice exhibit a decrease of stability of the odor-reward association when NE activity is decreased, evidenced by less perseverance when odor-reward associations are reversed and by shorter duration of the acquired memory. The testing for memory stability was performed without manipulations of local NE and any effects of decreased NE activity were because of differences in acquisition. To ensure that our optogenetic manipulations were effective and to determine which bulbar NE receptors were mediating the observed effects, we then repeated the memory duration experiment using local infusions of NE antagonists. Perseverance and duration are two aspects of memory stability. Next, we show another aspect of memory stability, the specificity of the memory for the learned odor, which is also dependent on bulbar NE influx. A proof of concept model for odor learning driven by a realistic well vetted computational model of olfactory processing and its modulation by NE shows that our diverse behavioral results can be mediated by NE-driven changes in neural dynamics. The novelty of our results is showing that very temporary changes in neuromodulation can have a variety of long-lasting effects resulting from the same neural mechanism and that changes in very early sensory networks can have far-reaching effects.

\section{Materials and Methods}

Optogenetic experiments (experiments 1 and 2)

Animals

Twelve adult male C57BL6/J mice (Charles River Laboratories) that were 2 months of age at the beginning of the experiments were used for this experiment. Mice were housed in standard laboratory cages and were kept on a $12 \mathrm{~h} \mathrm{light/dark} \mathrm{cycle} \mathrm{(at} \mathrm{a} \mathrm{constant} \mathrm{temperature} \mathrm{of} 22^{\circ} \mathrm{C}$ ) with food and water ad libitum except during behavioral tests during which they were food deprived ( $\sim 20 \%$ reduction of daily consummation, leading to a $10 \%$ reduction in body weight). Mice were housed by group of five, and individually after surgery. All experimental procedures were validated by Lyon 1 and the French Ethical Committee (protocol \#DR2013-48).

Odorants

Seven pair of odorants were used in these experiments. Odorants were diluted in mineral oil to achieve an approximate gas-phase partial pressure of $10 \mathrm{~Pa}$ (Cleland et al., 2002; Kermen et al., 2011; Table 1).

Viral vector injection and optical fiber implantation

Before surgery, mice were anesthetized with a cocktail injection of $50 \mathrm{mg} / \mathrm{kg}$ ketamine and $7.5 \mathrm{mg} / \mathrm{kg}$ xylazine administered intraperitoneally and secured in a stereotaxic instrument (Narishige). Three hundred nanoliters of hSyn-eNpHR3.0-EYFP lentivirus $\left(9.22 \times 10^{6} \mathrm{IU} / \mathrm{ml}\right.$, expressing halorhodopsin and the yellow fluorescent protein; $\mathrm{NpHR}$ mice, $n=7)$ and $300 \mathrm{nl}$ of control (Ctrl) hSyn-EYFP lentivirus [1.1 $\times$ $10^{6} \mathrm{IU} / \mathrm{ml}$, expressing only enhanced yellow fluorescent protein (EYFP); Ctrl mice, $n=5$ ] were injected bilaterally into the locus coeruleus at the following coordinates with respect to the bregma: anteroposterior (AP), $\pm 5.4 \mathrm{~mm}$; mediolateral (ML), \pm 0.9 ; dorsoventral (DV), $-4 \mathrm{~mm}$ at a rate of $150 \mathrm{nl} / \mathrm{min}$. In all mice, bilateral optical fibers [core diameter, $200 \mathrm{nM}$; 0.22 numerical aperture (NA); Doric Lenses] were implanted into the OBs (from bregma: AP, $+4.6 \mathrm{~mm}$; ML, $\pm 0.75 \mathrm{~mm}$; DV,$-2 \mathrm{~mm}$; Fig. $1 A$ ). Behavioral experiments were performed 8 weeks after surgery. The pLenti-hSyn-eNpHR3.0-EYFP lentivirus was a gift from Karl Deisseroth (Stanford University: Stanford, CA) (Gradinaru et al., 2010) and was obtained through Addgene (plasmid \#26775). Elaboration of the control
Table 1. Odorants and dilutions used for experiments 1-3

\begin{tabular}{lll}
\hline Odor sets & Odorant 1 (\%v/v) & Odorant 2 (\%v/v) \\
\hline 1 & Decanal (17.76) & + Limonene (2.0) \\
2 & Anisole (0.5) & Amyl acetate (0.7) \\
3 & Pentanal (0.07) & Butanal (0.02) \\
4 & Hexanoic acid (14.9) & Pentanoic acid (4.5) \\
5 & Heptanol (8.4) & Octanol (26.7) \\
6 & Butyl pentanoate (5.7) & Butyl hexanoate (16.3) \\
7 & Butanol (0.2) & Pentanol (0.7) \\
\hline
\end{tabular}

The table shows the odors used and the percentage $\mathrm{v} / \mathrm{v}(\% \mathrm{v} / \mathrm{v})$ dilutions used to obtain approximate vapor partial pressures of $10 \mathrm{~Pa}$.

pLenti-hSyn-EYFP lentivirus has been previously described (Kermen et al., 2016). The expression of light-sensitive chloride pumps and the delivery of light to axonal projection targets has been successfully used to inhibit activity at presynaptic terminals (Spellman et al., 2015; Stuber et al., 2011; Tye et al., 2011; Raimondo et al., 2012).

\section{Behavioral procedure}

Apparatus. Behavioral training took place on a computer-assisted two-hole board apparatus described previously (Mandairon et al., 2009). The hole board is equipped with capacitive sensors that monitor the events of nose poking (visits) in the holes. The holes were odorized by placing a cotton swab impregnated with $60 \mu \mathrm{l}$ of $10 \mathrm{~Pa}$ odorant under bedding in a small dish placed into the hole. A food reward was buried into the bedding of one of the holes, with the location of the odor reward randomly determined for each trial.

Shaping. The mice were first trained to retrieve a reward (a small bit of sweetened cereal; Kellogg's) by digging through the bedding. The mouse was put in the start area of the two-hole board apparatus and allowed to dig for $1 \mathrm{~min}$. During the first few trials, the reward was placed on top of the bedding in one of the holes. After the mice successfully retrieved the reward several times, it was successively buried deeper and deeper in the bedding. Shaping was considered to be complete when a mouse could successfully retrieve a reward buried deep in the bedding for at least 16 of 20 trials. Odor set 1 (Table 1) was used for shaping.

Acquisition. Each session consisted of 1 min trials during which the mouse was allowed to retrieve the food reward from the hole. If a mouse failed to find the reward after $60 \mathrm{~s}$, the trial was ended and the mouse replaced on the starting position behind a cover while the next trial was set up. The inhibition of NA fibers in the $\mathrm{OB}$ was performed by bilateral continuous light stimulation (crystal laser: $561 \mathrm{~nm}, 10-15 \mathrm{~mW}$ ) automatically triggered by the entry of the mouse's nose within a $5 \mathrm{~cm}$ zone around the odorized hole (light-triggering zone; VideoTrack, Viewpoint) and stopped automatically when the nose of the mouse exited the zone.

Reversal test. Mice were first trained for 10 trials of $1 \mathrm{~min}$ (see Acquisition) on an odor-reward association immediately followed by 15 trials with reversed odor-reward contingency (experiment 1). Optical stimulation was used for the initial 10 acquisition trials only. Mice were tested using odor set 6 with odor $1(\mathrm{O} 1)$ associated with the reward in the first 10 trials and $\mathrm{O} 2$ associated with the reward for the last 10 trials. Each mouse was tested once.

Long-term memory test. Mice were trained with optical stimulation during the 20 acquisition trials and tested without optical stimulation for 5 trials 2 and $24 \mathrm{~h}$ later (experiment 3). Each mouse was tested twice in this experiment, once with odor set 3 and once with odor set 4, with O1 for each odor set associated with reward. A control experiment tested the role of $\mathrm{NE}$ inputs to the $\mathrm{OB}$ for recall: mice were trained during 20 trials without optical fiber stimulation and tested at 2 and $24 \mathrm{~h}$ with optical stimulation. Each mouse was tested once in this experiment, using odor set 5, with $\mathrm{O} 1$ associated with reward. In a control experiment, mice were first trained during 20 trials without optical stimulation and tested 2 and $24 \mathrm{~h}$ later with optical stimulation (odor set 2; Table 1).

Experimental design and statistical analysis. In experiments 1 and 2, 12 male mice ( 5 controls and $7 \mathrm{NpHR}$ mice) were tested. Mice were tested twice with separate odor sets in experiment 2 . All statistical analyses were performed using SPSS. Analysis was performed on the latency (delay) to dig in the rewarded dish as the dependent variable. The 
A

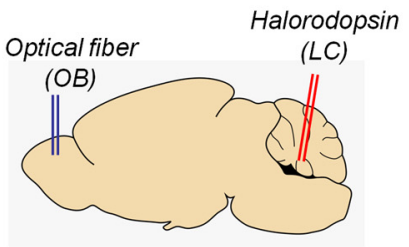

B

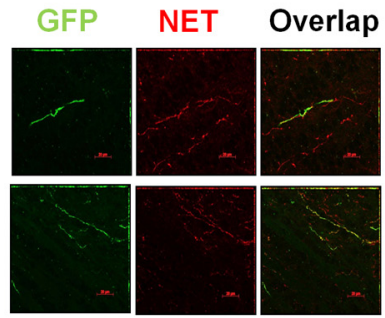

$D_{i} \quad$ Light ON

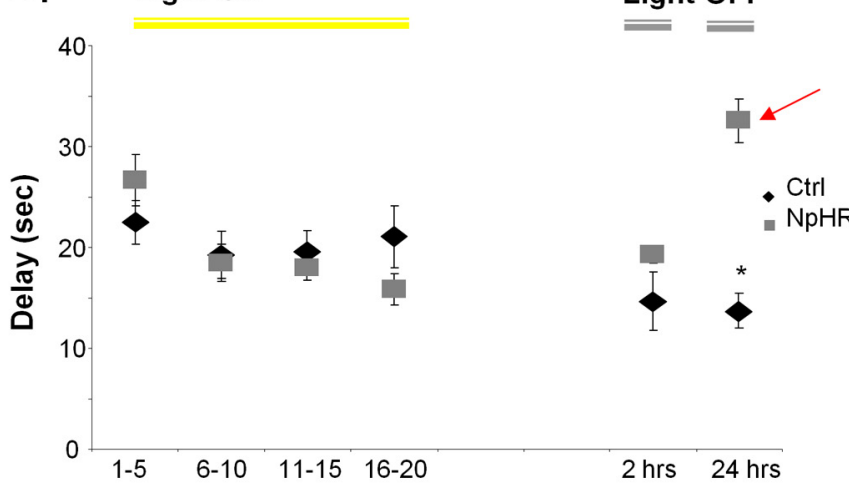

Trial block
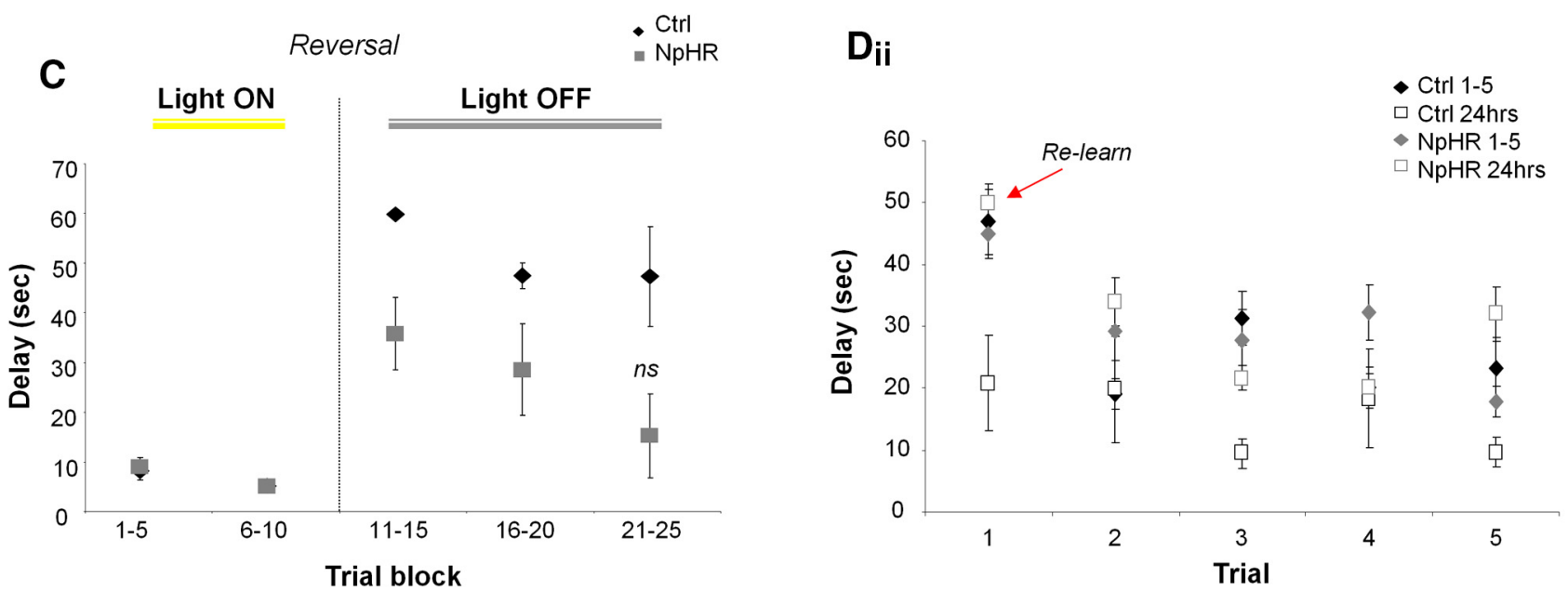

Figure 1. Optogenetic experiments showed decreased memory stability after NE inhibition during acquisition. $\boldsymbol{A}$, Viral vectors were injected directly into the locus coeruleus, and optical fibers were implanted in the OBs. $\boldsymbol{B}$, Viral transfection in NE fibers terminating in the OB. GFP, NET, and overlap between GFP and NET images in the OB. C, Reversal experiment. The graph shows the average delay to find the rewarded odor as a function of trial block. Odor-reward contingency was reversed after two trial blocks (reversal). Optogenetic blockade of NE inputs was performed only during the initial 10 trials (trial blocks $1-5$ and $6-10$, Light $0 \mathrm{~N}$ ), not during reversal training. Control mice with NE modulation not affected by light stimulation did not learn the new odor-reward association, whereas NpHR mice (NE modulation decreased by optogenetic stimulation) acquired the new association after 15 trials. $\boldsymbol{D}_{i,}, \boldsymbol{D}_{i i,}$, Duration of odor memory is shortened when bulbar NE is decreased. $\boldsymbol{D}_{\boldsymbol{i}}$, The graph shows the average delay to find the rewarded odor as a function of trial block for both experimental groups. Optogenetic decrease of NE inputs to the $O B$ (Light $0 \mathrm{~N}$ ) was performed during 20 acquisition trials (trial blocks 1-5, 6-10, 11-15, 16-20) but not during recall trials 2 and $24 \mathrm{~h}$ after the end of acquisition (Light $0 \mathrm{FF}$ ). Note that in NpHR animals the delay to find the rewarded odor was increased to the level during initial acquisition at the $24 \mathrm{~h}$ test block. $\boldsymbol{D}_{i i}$. Experimental animals relearn the task at the $24 \mathrm{~h}$ delay block. The graph shows average delays to find the rewarded odor during the first five acquisition trials (Ctrl trials, 1-5; NpHR trials, 1-5) and during the five trials at the $24 \mathrm{~h}$ recall test (Ctrl, $24 \mathrm{~h}$; NpHR, $24 \mathrm{~h}$ ). Note that NpHR mice perform similarly during these two blocks showing that they relearn rather than recall the odor-reward association. Data are available in Extended Data Figure 1-1.

latency to dig in the rewarded dish is a good indicator for the strength of the acquired memory, with short latencies signaling a strong memory and fast decision-making, and longer latencies signaling slower decisionmaking and weaker learning (Mandairon et al., 2018). Repeated-measures ANOVA was used to assess how the blockade of NE projections modulates acquisition or recall. In each case, the experimental group (control or $\mathrm{NpHR}$ ) was used as the between-subjects factor, and trial block (TB) or trial number as the within-subjects factor $(\alpha=0.05)$. Pairwise comparisons between trial blocks to assess acquisition and recall were performed using Wilks' $\lambda$ with $\alpha=0.05$. Successful reversal learning was assessed by comparing the delays during the last acquisition trial block (trials 6-10) to those during the last reversal trial block (trials 21-25). Long-term memory was assessed by comparing delays during the last acquisition trial block (trials 16-20) to those at 2 and $24 \mathrm{~h}$. All raw data used for statistical analysis are available in Extended Data Fig. 1-1.

Cellular analysis. Mice were killed using pentobarbital $(0.2 \mathrm{ml} / 30 \mathrm{~g})$ and intracardiac perfusion of $50 \mathrm{ml}$ of fixative (PFA 4\%), $\mathrm{pH} 7.4$. The brains were removed, postfixed overnight, cryoprotected in sucrose
(20\%), frozen rapidly, and then stored at $-20^{\circ} \mathrm{C}$ before sectioning with a cryostat. Immunohistochemistries of NET (NE-Transporter to label NE fibers) and EYFP (to label transduced fibers) were performed in four to six sections ( $40 \mu \mathrm{m}$ thick) of the OB distributed along its anteroposterior axis, using anti-NorEpinephrin Transporter (mouse; 1/1000; MAb Technologies) and anti-GFP (chicken; 1/1000; AnaSpec/Tebu). Appropriate secondary antibodies were used (goat anti-mouse Alexa Fluor 546 vector (1/250); and goat anti-chicken Alexa Fluor 488 (1/250); Thermo Fisher Scientific). Sections were then cover-slipped in Vectashield (Vector Laboratories). All fluorescent analyses were performed blind with regard to the identity of the animal. Images were taken in the granule cell (GC) layer of the $\mathrm{OB}$ with a Zeiss microscope equipped with an apotome, using $40 \times$ oil-immersion objective. $Z$-stacks were acquired with a $0.2 \mu \mathrm{m}$ interval between images. Eight to thirteen pictures per animal were analyzed. Length of NET-positive and NET/GFP-positive fibers were analyzed with $3 \mathrm{D}$ viewer in ImageJ and NET/GFP-positive fibers among NET-positive fibers assessed (Fig. 1B). No animal was excluded from the analysis. The amount of overlap between GFP and NET expressing fibers was similar in 
Table 2. Odorants and dilutions used for experiment 4

\begin{tabular}{cllll}
\hline Odor sets & C (\%v/v) & C + 1 (\%v/v) & C + 2 (\%v/v) & $X(\% v / v)$ \\
\hline 8 & Propanoic acid (0.33) & Butanoic acid (1.3\%) & Pentanoic acid (4.5) & 3 -heptanone (0.6) \\
9 & Hexyl acetate (2.28) & Amyl acetate (0.7) & Butyl acetate (0.2) & Anisole (0.5) \\
10 & Pentanol (0.74) & Hexanol (2.6) & Heptanol (8.4) & Benzylamine (2.9) \\
11 & Hexanoic acid (14.9) & Heptanoic acid (46.8) & Octanoic acid (13.7) & Neryl acetate (16.4) \\
12 & Pentyl butyrate (5.8) & Hexyl butyrate (16.3) & Heptyl butyrate (46.0) & + Carvone (47.2) \\
13 & Hexanal (0.24) & Heptanal (0.72) & Octanal (1.48) & Trans-2 hexenyl acetate (26.7) \\
\hline
\end{tabular}

The table shows the odors used and the percentage $\mathrm{v} / \mathrm{v}(\% \mathrm{v} / \mathrm{v})$ dilutions used to obtain approximate vapor partial pressures of $10 \mathrm{pa}$.

Ctrl (mean \pm SEM, $24.5 \pm 3.85 ; n=5)$ and NpHR (mean \pm SEM, 16.36 $\pm 4.90 ; n=7)$ mice $\left(F_{(1,10)}=1.827 ; p=0.206\right)$.

\section{Pharmacological experiments}

Animals

Twelve (experiment 3) and 9 (experiment 4) adult male C57BL6/J mice (Charles River Laboratories) that were 2 months of age at the beginning of the experiments were used for pharmacological experiments. Mice were housed in standard laboratory cages and were kept on a $12 \mathrm{~h}$ light/ dark cycle with food and water available ad libitum except during behavioral test where they were food deprived to no less than $85 \%$ of their free feed weight. All experimental procedures were conducted under a protocol approved by the Cornell University Institutional Animal Care and Use Committee.

\section{Odorants}

Odorants are listed in Tables 1 and 2. Before each behavioral session, $60 \mu \mathrm{l}$ of odor was loaded into $5 \mathrm{ml}$ of sand and then covered with an additional $5 \mathrm{ml}$ of sand.

\section{Cannulation surgery}

After behavioral shaping and before experiments, mice underwent surgery to implant bilateral cannulae in the OB for drug delivery according to established methods. Mice were anesthetized with gas anesthesia (isoflurane, $2-4 \%$ ), injected intraperitoneally with $0.05 \mathrm{mg} / \mathrm{kg}$ atropine, and guide cannulae (22 gauge; Plastics One) were inserted $5 \mathrm{~mm}$ anterior and $1.5 \mathrm{~mm}$ ventral from bregma and affixed to the skull with dental cement (Guérin et al., 2008; Tong et al., 2018). After surgery, mice were given pain killers and saline injections and were allowed to recover for $7 \mathrm{~d}$.

\section{Drug infusions}

Twenty minutes before behavioral testing, mice were bilaterally infused with NE antagonists or saline. Two microliters of solution was infused at $1 \mu \mathrm{l} / \mathrm{min}$, and the infusion needle was left in place for 5 min after infusion. For long-term memory testing, mice were infused with saline, the $\alpha 1$-blocker prazosin (hydrochloride, $1 \mathrm{~mm}$ ), the $\alpha 2$-blocker yohimbine (hydrochloride, $2 \mathrm{~mm}$ ), the $\beta$-antagonist alprenolol (hydrochloride, $12 \mathrm{~mm}$ ) or a cocktail of all three, all purchased from Sigma-Aldrich and diluted in $0.9 \%$ saline. For specificity testing, mice were infused with the nonspecific $\alpha$-antagonist phentolamine (12 mM) or saline, with dosages determined from our previous behavioral experiments (Mandairon et al., 2008; Escanilla et al., 2010, 2012).

\section{Experimental procedure}

Behavioral testing took place in a modified mouse cage with a start and a testing chamber separated by an opaque removable Plexiglas door. Mice were put into the start chamber with the door closed and Petri dishes with a sand-odor mix were placed into the test chamber with a sugar pellet in the rewarded odor dish. The divider was opened, and mice were allowed to dig in the dishes to retrieve the sugar reward. The time delay to dig in the correct dish was recorded by hand and later double checked on the video trace. Mice were shaped to dig until they consistently retrieved the reward for 18 of 20 trials. For long-term memory tests, each mouse was trained for 20 trials using two scented dishes, one rewarded and one not, and tested on five trials $24 \mathrm{~h}$ later. Odor sets 1 and 2 were used for shaping and odor sets 3-7 were used for the experimental trials. Each mouse was tested on each drug condition (saline, $\alpha 1$ blocker, $\alpha 2$-blocker, $\beta$-blocker, all blockers) with a different odor set; the order of drug conditions was pseudorandomized and counterbalanced among mice. For specificity testing, each mouse was trained on an odor-reward association with a straight chain aliphatic odorant (C) for 4,8 , or 12 trials paired with an unscented dish, immediately followed by unrewarded test trials with the conditioned odor (C), two similar odors differing by one or two carbons from the conditioned odor $(\mathrm{C}+1$ and $\mathrm{C}+2$ ) and one unrelated odor (X; Table 2). Each mouse was trained and tested under each drug condition and number of training trials with a different odor set, with order of drug conditions, number of trials, and number of odor sets randomized and counterbalanced.

Experimental design and statistical analysis

Experiment 3 used 12 male mice who were each tested on each of five drug conditions. To test for the role of NE receptors in acquisition and $24 \mathrm{~h}$ recall, we used repeated-measures ANOVAs with latency to dig in the correct dish as the dependent variable, drug group as the betweensubjects factor, and trial block or trial number as the within-subjects factor $(\alpha=0.05)$, followed by pairwise comparisons between trial blocks to assess acquisition and recall using Wilks' $\lambda$. Memory at the 2 and $24 \mathrm{~h}$ tests was assessed by comparing delays to find the rewarded odor during the last acquisition trial block (trials 16-20) to the 2 and $24 \mathrm{~h}$ trial block. Experiment 4 used nine male mice who were tested on each drug/number of trial combination $(2 \times 3$ design). For specificity testing, data were analyzed using a repeated-measures analysis with drug group (saline or phentalomine) and number of training trials $(4,8$, or 12$)$ as betweensubjects factors and digging times in response to unrewarded test odors $(\mathrm{C}, \mathrm{C}+1, \mathrm{C}+2$, and $\mathrm{X})$ as within-subjects factor, followed by pairwise comparisons between digging responses in the conditioned and novel odors for each group (Wilks' $\lambda$ ) to assess memory specificity for the conditioned odor. All data analysis was performed in SPSS. All raw data used for statistical analysis is available in Extended Data Fig. 1-1.

\section{Note on behavioral experiments}

All behavioral experiments used a similar paradigm in which mice have to find a buried reward in an odorized dish. The details of the procedure (hole board vs modified home cage) and the number of trials differed between experiments. In experiment 1 , we aimed to have acquisition complete without much overtraining to allow for reversal, if possible, and therefore chose 10 acquisition trials followed by 15 reversal trials. In experiments 2 and 3, we aimed to have enough trials for long-term $24 \mathrm{~h}$ memory to exist without overtraining the animals to be able to see an effect of NE modulation; we chose to train mice for 20 trials (Tong et al., 2018). In experiment 4 , mice were trained on the odor-reward association with a scentless distracter odor because in this experiment we used a method to test how mice generalize between odorants (Linster and Hasselmo, 1999; Cleland et al., 2002), and we used a range of training trials $(4,8$, and 12$)$ to show that mice remember the odor more specifically when trained longer (Cleland et al., 2011; Cho and Linster, 2020). In each case the number of training trials was chosen based on experience to maximize the chance to see an effect and to avoid floor and ceiling effects.

\section{Computational modeling}

Computational modeling of the olfactory bulb followed the outline presented in the study by Linster and Kelsch (2019), with detailed equations and parameter sets described below, and the associated parameters described in Table 3. The modeled OB network incorporates the 
Table 3. Computational modeling parameters

\begin{tabular}{|c|c|}
\hline$\overline{\mathrm{OSN}}$ & $\tau=1 \mathrm{~ms} ; \mathrm{V}_{\text {rest }}=-65 \mathrm{mV} ; \theta^{m i} n=-65 \mathrm{mV} ; \theta^{\max }=-55 \mathrm{mV}$ \\
\hline Mitral & $\begin{aligned} \tau & =5 \mathrm{~ms} ; \mathrm{V}_{\text {rest }}=-65 \mathrm{mV} ; \theta^{m i} n=-64 \mathrm{mV} ; \theta^{\max } \\
& =-57 / 61 \mathrm{mV}^{*}\end{aligned}$ \\
\hline PGs & $\tau=2 \mathrm{~ms} ; \mathrm{V}_{\text {rest }}=-65 \mathrm{mV} ; \theta^{m i} n=-65 \mathrm{mV} ; \theta^{\max }=-60 \mathrm{mV}$ \\
\hline GC & $\begin{array}{l}\tau=4 \mathrm{~ms} ; \mathrm{V}_{\text {rest }}=-65 \mathrm{mV} ; \theta^{m i} n=-65.2 /-66 \mathrm{mV} \\
\quad \theta^{\max }=-60 \mathrm{mV}\end{array}$ \\
\hline ETs & $\tau=2 \mathrm{~ms} ; \mathrm{V}_{\text {rest }}=-65 \mathrm{mV} ; \theta^{m i} n=-65 \mathrm{mV} ; \theta^{\max }=-60 \mathrm{mV}$ \\
\hline Pyr & $\begin{aligned} \tau & =10 \mathrm{~ms} ; \mathrm{V}_{\text {rest }}=-65 \mathrm{mV} ; \theta^{m i} n=-62 \mathrm{mV} ; \theta^{\max } \\
& =-55 \mathrm{mV} /-60 \mathrm{mV}^{*}\end{aligned}$ \\
\hline OSN to $P G$ & $\mathrm{w}=0.003 ; \mathrm{E}_{\mathrm{N}}=+70 \mathrm{mV} ; \tau_{1}=1 \mathrm{~ms} ; \tau_{2}=2 \mathrm{~ms}$ \\
\hline OSN to Mi (apical) & $\mathrm{w}=0.006 ; \mathrm{E}_{\mathrm{N}}=+70 \mathrm{mV} ; \tau_{1}=1 \mathrm{~ms} ; \tau_{2}=2 \mathrm{~ms}$ \\
\hline OSN to ET (apical) & $\mathrm{w}=0.0006 ; \mathrm{E}_{\mathrm{N}}=+70 \mathrm{mV} ; \tau_{1}=1 \mathrm{~ms} ; \tau_{2}=2 \mathrm{~ms}$ \\
\hline PG to Mi (apical) & $\mathrm{w}=0.003 ; \mathrm{E}_{\mathrm{N}}=-5 \mathrm{mV} ; \tau_{1}=2 \mathrm{~ms} ; \tau_{2}=4 \mathrm{~ms}$ \\
\hline ET to Mi (apical) & $\mathrm{w}=0.0015 ; \mathrm{E}_{\mathrm{N}}=70 \mathrm{mV} ; \tau_{1}=1 \mathrm{~ms} ; \tau_{2}=2 \mathrm{~ms}$ \\
\hline Mi (soma) to GC & $\mathrm{w}=0.004 ; \mathrm{E}_{\mathrm{N}}=+70 \mathrm{mV} ; \tau_{1}=1 \mathrm{~ms} ; \tau_{2}=2 \mathrm{~ms} ; p=0.2$ \\
\hline $\mathrm{GC}$ to $\mathrm{Mi}$ (soma) & $\mathrm{w}=0.004 ; \mathrm{E}_{\mathrm{N}}=-5 \mathrm{mV} ; \tau_{1}=2 \mathrm{~ms} ; \tau_{2}=4 \mathrm{~ms}$; local only \\
\hline Mi (soma) to RN & $\mathrm{w}_{\text {naive }}=0.001 ; \mathrm{E}_{\mathrm{N}}=+70 \mathrm{mV} ; \tau_{1}=1 \mathrm{~ms} ; \tau_{2}=2 \mathrm{~ms}$ \\
\hline
\end{tabular}

Pyramidal, Pyr; membrane time constant, $\tau$; resting membrane potential, w; reversal potential, $\mathrm{E}_{N} ;$ rise time, $\tau_{1}$; decay time, $\tau_{2}$; afterhyperpolarization magnitude, $\mathrm{A}^{\text {ahc }}$; calcium accumulation time constant, $\tau^{\text {ahc }}$ Mitral, $\mathrm{Mi}$

* Different values are without/with NE modulation, respectively.

following five neuron types: olfactory sensory neurons (OSNs), mitral cells (MCs), external tufted cells (ETs), periglomerular cells (PGs), and GCs. Each group is composed of 100 neurons organized in functional columns with connectivity parameters that are specified in Table 3. MCs make synapses with $25 \%$ of GCs $\left(p_{\text {MC-GC }}=0.25\right)$, and GCs make inhibitory local synapses onto MCs only. NE modulation to the OB was modeled according to the principles we discovered previously in brain slice and computational experiments (Nai et al., 2009, 2010; Linster et al., 2011); here, we simulated a high dosage of NE resulting in a dominance of $\alpha 1$-receptor effects on GC and MCs, which is also in agreement with the results from the pharmacological experiments presented here. Briefly, NE $\alpha 1$ modulation increases MC excitability with no change in membrane voltage or spontaneous activity, and increases GC activation with an increase in voltage and spontaneous activity (Nai et al., 2009, 2010; Linster et al., 2011). Learning an odor-reward association was modeled by projecting MC outputs in response to a conditioned stimulus (CS) to a response neuron (RN) that also received "reward" information [unconditioned stimulus (US); see Fig. 4A]. Excitatory synapses between MCs and the RN underwent activity-dependent synaptic plasticity when reward was present as well as a slow exponential decay toward baseline when reward was not present. This exponential decay had a time constant of $10 \mathrm{~d}$, which resulted in memory durations similar to those observed experimentally for control mice and control simulations (NE). Reward association learning was simulated as follows. For each simulated "trial block" (five trials of $30 \mathrm{~s}$ each), the conditioned odor was paired with reward (activation of RN by US), which resulted in changes in synaptic weights between MCs and RN. After each trial block, we then set the reward to zero and presented the $\mathrm{C}$, two overlapping odors with varying degree of overlap $(C+1, C+2 ; 78 \%$ response; $34 \%$ correlation with $\mathrm{C}$ ), and an unrelated odor (X; -0.42 correlation with $\mathrm{C}$ ) for one simulated trial, computed the resulting activation of the RN (Devore et al., 2014), and saved the synaptic weight amplitudes. This was repeated over the course of four trial blocks ( 20 trials total) to test to what degree the specificity of the association evolved as a function of learning and depends on the presence of NE. Memory duration in the model was assessed by presenting the conditioned odor at intervals of $1 \mathrm{~h}$ simulated during a $24 \mathrm{~h}$ forgetting time. We ran 10 different instances of the model, each initialized with a different seed for the random number generator.

\section{Analysis}

To assess memory duration, we statistically compared RN response amplitudes (spiking probabilities) during preacquisition testing to that during each segment of the $24 \mathrm{~h}$ forgetting period. To assess memory specificity, we statistically compared $\mathrm{RN}$ response magnitudes to conditioned and test odors after each trial block during acquisition.
Network architecture

The modeled $\mathrm{OB}$ network incorporates the following five neuron types: OSNs, MCs, ETs, PGs, and GCs. Each group is composed of 100 neurons organized in functional columns. MCs make synapses with $25 \%$ of GCs ( $\mathrm{p}_{\text {MC-GC }}=0.25$ ), and GCs make inhibitory local synapses only (McIntyre and Cleland, 2016). To assess associations between odors (CS) and rewards (US), an RN was added that received excitatory synaptic inputs with very low initial weights from all MCs and underwent activity-dependent synaptic plasticity when US and CS were present at the same time. During postacquisition, when no US was present, these synapses underwent a slow exponential decay back to baseline values. The response magnitude of the $\mathrm{RN}$ was measured as instantaneous spiking probabilities.

\section{Neurons and synapses}

Our model is composed of single compartment leaky integrate-and-fire neurons, with the exception of $\mathrm{MC}$ which are modeled as two compartments. Changes in membrane voltage $\mathrm{v}(\mathrm{t})$ over time in each compartment are described by Equation 1:

$$
\tau \frac{d v(t)}{d t}+v(t)=V^{e x t}(t)
$$

where $\tau$ is the membrane time constant and $V^{\text {ext }}(t)$ is the voltage change resulting from external inputs (synaptic or sensory).

Each one of the voltage changes because of external inputs $V^{\text {ext }}$ is a result of the synaptic strength of the connection from neuron $j$ to neuron $i\left(w_{i j}\right)$, and the respective synaptic conductance in cell $i$ at time $t\left(g_{i}(t)\right) . E_{N, i j}$ is the Nernst potential of the synaptic current, and $v_{i}(t)$ is the membrane potential of the postsynaptic neuron $i$, as described in Equation 2:

$$
V_{i}^{\mathrm{ext}}(t)=w_{i j} g_{i}(t)\left[E_{N i j}-v_{i}(t)\right]
$$

The communication between neurons happens via discrete spikes. The spiking output $F(5)$ of a given neuron, $I$, is a function of its membrane potential $v$ and the minimal threshold and saturation threshold of the output function, $\theta^{\min }$ and $\theta^{\max }$, where $F_{i}(5)=0$ if $v \leq \theta^{\min }$ and $F_{i}(5)=1$ if $v \geq \theta^{\max }$ and $\operatorname{Fi}(5)$ increases linearly between $\theta_{\min }$ and $\theta_{\max }$

$F_{\mathrm{i}}(5)$ defines their instantaneous firing probability. The time course of the conductance change is calculated as follows:

$$
g_{i}(t)=g^{\max }\left(e^{-\frac{t}{\tau_{1}}}-e^{-\frac{t}{\tau_{2}}}\right)
$$

where $g^{\max }$ is a constant with no unit representing the maximum conductance of a given channel and is equal to 1 (synaptic strength is scaled by the synaptic weight $w$ ), while $\tau_{1}$ and $\tau_{2}$ are the rising and falling times of this conductance. After firing, the spike of each spiking neuron is reset to the spiking threshold $\left(V_{\text {rest }}\right)$.

In the simulations presented here, simulated exposure to an odorant induced activity-dependent plasticity of synapses from MC to the RN. Synaptic strengths were first calculated from the parameters given in Table 1. During simulated trial blocks, synapses between MCs and the $\mathrm{RN}$ underwent synaptic potentiation, as follows:

$$
\mathcal{W}_{i j-n e w}=\mathcal{W}_{i j-o l d}+\alpha * \sum_{t 1}^{t 2} x_{i}(t) * \sum_{t 1}^{t 2} x_{j}(t)
$$

where $w_{i j}$ is the synaptic strength between the presynaptic MC and the postsynaptic RN, $\alpha(\alpha=0.01)$ is the rate of potentiation, and $x_{j}$ and $\xi$ are the total numbers of spikes emitted by the presynaptic and postsynaptic cells during the preceding sniff cycles between $t 1$ and $t 2$. The synaptic weights also undergo postsynaptic normalization after the weight changes have been computed, with the sum of synaptic weights from $\mathrm{MC}$ to RN staying constant; this creates competition between synaptic weights over the course of training and leads to increasing specificity of 
synaptic weights to the odor used for conditioning. Postacquisition synaptic weights decay exponentially with a long time constant $(10 \mathrm{~h})$ to simulate forgetting in the absence of US-CS pairings. This time constant was adjusted to result in a long-term memory of at least $24 \mathrm{~h}$ for simulations in which NE was present during acquisition.

\section{Implementation}

All simulations were implemented using the $\mathrm{C}$ programming language in a Linux environment (Ubuntu 14.04 LTS x64) on an Intel desktop computer, with the Euler integration method used for the differential equations with a time step of $1 \mathrm{~ms}$.

\section{Data availability}

The code/software described in the article is freely available online at https://senselab.med.yale.edu/modeldb/enterCode? model=266801. The code is available in Extended Data Fig. 2-1.

\section{Results}

We first show that memory stability depends on bulbar LC inputs by optogenetically decreasing NE fiber activity in the OB while testing mice on a reversal task (experiment 1 ) and a longterm memory task (experiment 2). We then use a pharmacological approach to show that our optical manipulation was effective and to narrow down NE receptor types underlying our observations (experiment 3). Last, we show that memory stability as expressed by the specificity of this memory is modulated by bulbar NE (experiment 4) and use a computational approach to propose a single mechanism that could underlie all of these observations.

\section{NE inhibition in the olfactory bulb decreases odor memory stability expressed as perseverance in response to change}

Experiment 1 tested how stable a memory acquired after a training period of 10 trials is by using a reversal training paradigm. $\mathrm{NpHR}$ and Ctrl mice were trained under light stimulation (with optical stimulation $\mathrm{ON}$ when the nose of the mouse was within a $5 \mathrm{~cm}$ radius of each odor dish) in a 10-trial simultaneous go-nogo task (Escanilla et al., 2008; Chaudhury et al., 2009; Moreno et al., 2012; Mandairon et al., 2018) in which they had to associate odorant 1 with a reward while odorant 2 was not reinforced (odor set 6; Table 1). These 10 trials were immediately followed by 15 trials of reversal learning with no light stimulation in which odorant 1 was not reinforced and odorant 2 was rewarded. The latency to find the rewarded odorant was recorded as a measure for how well the odor-reward association was learned. A repeated-measures ANOVA showed an overall effect of trial block $\left(F_{\text {trialblock }(4,3)}=15.958 ; p=0.023\right)$ and a significant interaction with experimental group $\left(F_{\text {trialblock*group }(4,3)}=5.835 ; p=\right.$ 0.049), showing that how mice behaved over the course of trials depended on treatment. Both experimental groups rapidly acquired the odor-reward association as evidenced by significant decreases in delay to find the rewarded odor between the first and last trial blocks ( $1-5$ vs $6-10$; Ctrl: $p=0.002$; and NpHR: $p=0.042$; by Wilks' $\lambda$; Fig. $1 C$ ). During reversal learning, Ctrl mice showed a high degree of perseverance to the previously learned association even after 15 trials, evidenced by a significant increase in delay between the last acquisition and the last reversal trial blocks (6-10 vs $21-25 ; p=0.034$ ), whereas NpHR mice quickly learned the new odor-reward association, as evidenced by similar delays during the last acquisition and the last reversal trial block ( $6-10$ vs $21-25 ; p=0.268$; Fig. $1 C$ ). Thus, mice with decreased NE during acquisition were more flexible during reversal.
These results show that the stability of the acquired memory is less persistent for NpHR compared with Ctrl animals; while the effects of inhibiting bulbar NE are not evident during the initial acquisition of an odor-reward association, they manifest during reversal training, although $\mathrm{NE}$ is not modulated at that time.

\section{NE inhibition in the olfactory bulb decreased odor memory stability expressed as memory duration}

Experiment 2 tested how the presence of NE during learning affects the duration of the odor memory. We trained the same mice for 20 acquisition trials on the same task (odor sets 3 and 4; Table 1). We tested their recall ability 2 and $24 \mathrm{~h}$ later (Fig. 1Di). $\mathrm{NE}$ transmission in the OB was light inhibited for NpHR mice during the acquisition but not the recall trials. For acquisition trials, there was no significant interaction between the trial block and the experimental group $\left(F_{\text {trialblock } * \operatorname{group}(3,20)}=0.915 ; p=\right.$ 0.081 ) showing that NpHR and Ctrl groups behaved similarly during acquisition. Both groups had significantly lower delays at the $2 \mathrm{~h}$ test than at the beginning of acquisition (trials $1-5$ vs $2 \mathrm{~h}$; $p=0.041$ and 0.010 ) showing that the odor-reward association was remembered $2 \mathrm{~h}$ later. However, $24 \mathrm{~h}$ after training, $\mathrm{NpHR}$ mice exhibited delays as long as during initial training (trials 1-5 vs $24 \mathrm{~h} ; p=0.754)$, whereas Ctrl mice did not $(p=0.023)$, showing that while Ctrl mice remembered the association $24 \mathrm{~h}$ later, $\mathrm{NpHR}$ mice did not. Latencies to find the reward at the $24 \mathrm{~h}$ test were significantly increased compared with the $2 \mathrm{~h}$ test in $\mathrm{NpHR}$ ( 2 vs $24 \mathrm{~h} ; p=0.001$ ) but not control mice ( $p=0.649$; Fig. $1 \mathrm{Di}$ ). We directly compared performance during the first five acquisition trials and the five trials at the $24 \mathrm{~h}$ test: while control mice had significantly lower delays during the $24 \mathrm{~h}$ trials compared with the initial acquisition $\left(F_{(1,8)}=7.9 ; p=0.023\right)$, NpHR mice have similar delays in both cases $\left(F_{(1,11)}=3.037 ; p=0.109\right)$, showing that they relearned the task (Fig. 1Dii). A separate control experiment showed that NE inhibition during 2 or $24 \mathrm{~h}$ recall after acquisition without light inhibition did not affect the delays to find the correct odorant. Mice were first trained for 20 trials without light stimulation and underwent recall trials at 2 and 24 $\mathrm{h}$ with light stimulation. We found a significant effect of trial block $\left(F_{\text {trialblock }(3,7)}=6.000 ; p=0.017\right)$, but no interaction with group $\left(F_{\text {trialblock,group }(3,7)}=0.824 ; p=0.696\right)$ during acquisition showing that while both groups learned there was no difference in their acquisition curves. Neither group displayed significantly longer delays at $24 \mathrm{~h}$ than during the last acquisition trials (respectively, $p=0.669$ and $p=0.759$ ), showing that both groups remember the odor-reward association after $24 \mathrm{~h}$ and that the inhibition of NE release has no effect on recall.

These results show that while inhibition of bulbar NE release does not noticeably slow down acquisition of an odor-reward association, it does impair the duration of memory, confirming our hypothesis that the presence of NE during acquisition renders a memory more stable.

In experiment 3, to test the effectiveness of our manipulation and to identify NE receptors underlying the observed effects, we used a pharmacological approach. Mice $(n=12)$ were implanted with bilateral cannulae in the $\mathrm{OB}$ for intracerebral drug infusions and were tested using the same paradigm. In each training session, mice were trained for 20 trials with $\alpha 1, \alpha 2, \beta$, all, or no NE receptors blocked (Mandairon et al., 2008) and were tested $24 \mathrm{~h}$ later with a single five-trial block and no drug infusions (Fig. 2). Because of the longer time course of drug application, we omitted the $2 \mathrm{~h}$ test here. Results showed that all mice acquired the task similarly, but that mice with $\alpha 1$ receptors blocked during acquisition showed significantly longer delays to find the 
rewarded odor $24 \mathrm{~h}$ after training (Fig. 2). We found a significant effect of trial block $\left(F_{\text {trialblock }(4,28)}=16.078\right.$; $p<0.001)$ as well as an interaction between trial block and drug treatment $\left(F_{\text {trialblock*drug }(16,86.176)}=1.961 ; \quad p=0.025\right)$. Mice acquired the odor-reward association equally across drug treatments (comparison between delays to find rewarded odor during trials $1-5$ and trials $16-20 ; p<0.05$ for all drug conditions; Table 4, exact values). At the 24 recall test, mice in the saline, $\alpha 2$, and $\beta$ drug conditions showed significant recall (comparison between trials $1-5$ and 24 h; $p<0.05$; Table 4, exact values). In contrast, mice with $\alpha 1$ receptors or all receptors blocked did not exhibit significant recall after $24 \mathrm{~h}(p>0.05$; Table 4 , exact values). Hence, $\alpha 1$ receptor blockade locally in the OB had effects similar to those of the light inhibition of NE fiber activity locally in the $\mathrm{OB}$, showing that NE effects on longterm memory are mediated at least partially by $\alpha 1$ receptor activation, and that our light inhibition of NE release was effective.

\section{NE inhibition in the olfactory bulb decreases odor memory} stability as expressed in specificity for the learned odor Experiment 4 tested to what degree activation of NE receptors determines the specificity of an odor-reward association. We used a generalization task in which mice learn to associate an odor with reward and are later tested on novel odors to assess how specific the formed memory is (Cleland et al., 2002, 2009; Cleland and Narla, 2003; Mandairon et al., 2006; Chaudhury et al., 2009). Mice $(n=9)$ were implanted with bilateral cannulae in their OBs and were trained to associate an odorant with a reward during 4, 8 , or 12 trials. After the completion of training trials, mice were tested in four consecutive counterbalanced unrewarded trials with the $\mathrm{C}, \mathrm{C}+1$ and $\mathrm{C}+2$, and $\mathrm{X}$. How long mice search for the reward in a novel odor is a measure for how much they confuse the novel odor with the conditioned odor and, hence, assesses memory specificity (Linster and Hasselmo, 1999). Mice were trained after the infusion of saline (Fig. 3A) or the nonspecific $\alpha$ receptor blocker phentalomine into both OBs (Fig. $3 B$ ).

Saline-treated control mice showed higher specificity for the conditioned odor when trained longer: the perceptually most similar odor $(\mathrm{C}+1)$ was discriminated after 8 or 12 training trials, while the less similar $(\mathrm{C}+2)$ and the unrelated odor $(\mathrm{X})$ were discriminated after as few as four trials (Table 5, detailed $p$ values; Fig. 3A). In contrast, mice with NE receptors blocked the needed 12 training trials to discriminate the less similar odor $(C+2)$ and did not discriminate the most similar odor even after 12 acquisition trials (Table 5, detailed $p$ values; Fig. $3 B$ ). Overall, we found a strong effect of test odor $\left(F_{\text {odor }(3,29)}=14.063\right.$; $p<0.0001)$ as well as a significant interaction among test odor, drug treatment, and the number of conditioning trials $\left(F_{\text {odor*drug*\#trials }(3,58)}=3.023 ; p=0.046\right)$, with $p$ values for individual data points specified in Table 5. These data show that more training increases memory specificity, as does the presence of NE, supporting our hypothesis that NE can increase learning and therefore lead to effectively more stable memories (Fig. 3, Table 5).

Results from experiment 4 show that specificity for an odor memory increases when $\mathrm{NE}$ is unimpaired in the $\mathrm{OB}$ and that
Table 4. Summary of statistics for pharmacology long-term memory experiment

\begin{tabular}{lll}
\hline Repeated-measures ANOVA & $\begin{array}{l}\text { Acquisition* }(\text { Wilks' } \lambda) \\
\text { trials } 1-5 \text { vs } 16-20\end{array}$ & $\begin{array}{l}24 \mathrm{~h} \text { recall } \\
\text { trials } 1-5 \text { vs } 24 \mathrm{~h}\end{array}$ \\
\hline $\begin{array}{l}F_{\text {trialblock(4,28) }}=16.078 ; \\
p<0.001 ;\end{array}$ & Saline: $p=0.003$ & Saline: $p=0.001$ \\
$\begin{array}{l}F_{\text {trialblock*drug(16,86.176) }}=1.961 ; \\
p=0.025\end{array}$ & $\alpha 1: p=0.034$ & $\alpha 1: p=0.690$ \\
& $\alpha 2: p=0.012$ & $\alpha 2: p=0.022$ \\
& $\beta: p=0.004$ & $\beta: p=0.04$ \\
& All: $p=0.01$ & All: $p=0.430$ \\
\hline
\end{tabular}

* Significant decrease of delay between trials $1-5$ and $6-10$ indicates learning.

** Significant decrease between trials $1-5$ and $24 \mathrm{~h}$ indicate recall.

less training is needed to create highly specific odor memories. When NE is impaired, more training is needed and memory specificity generally decreases. Both the number of trials and the presence of NE modulated the stability of the formed memory, as expressed by its specificity to the learned odor.

\section{Summary of behavioral results}

Together, our behavioral data support the idea that the presence of NE allows for odor-reward associations to be more stable, leading to stronger perseverance, longer duration, and more specificity. We manipulate $\mathrm{NE}$ in the $\mathrm{OB}$ only and observe no direct acute effects of these manipulations. To understand how these seemingly different effects can arise, we propose a simple computational model of NE modulation and plasticity in the $\mathrm{OB}$, which shows that in principle a simple effect of NE can lead to the described long-term behavioral effects.

Olfactory bulb NE enhances synchrony and thereby learning, leading to increased memory stability, duration, and specificity We have shown multiple long-term behavioral effects of acute NE modulation in the olfactory bulb: more stable memories, longer-lasting memories, and more specific memories. To investigate the underlying neural mechanisms, we use an existing computational model of NE modulation in the OB (Escanilla et al., 2010; Linster et al., 2011; de Almeida et al., 2015; Linster and 
A

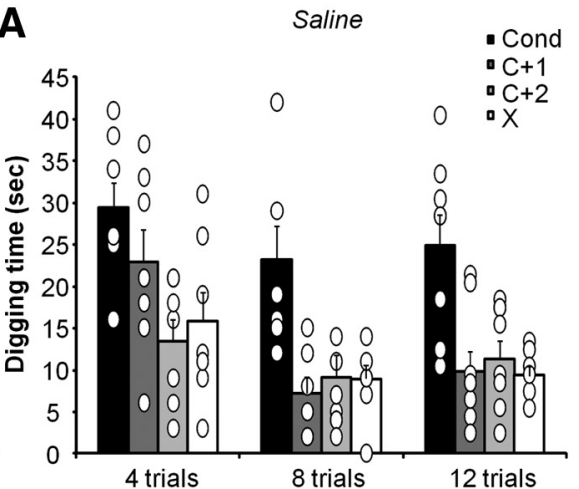

B

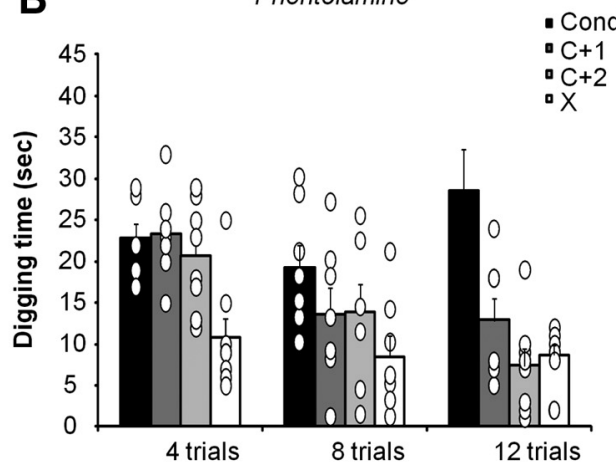

Figure 3. Odor memory specificity is decreased by NE receptor blockade in the OB. The graphs show the average time spent digging for the reward in scented dishes during unrewarded test trials. $\boldsymbol{A}$, Saline-treated control mice (Saline) differentiated between $C$ and $C+2 / X$ after as few as four training trials and differentiated $C+1$ after eight training trials. $\boldsymbol{B}$, In contrast, mice with NE receptors blocked (phentolamine) differentiated only X from C after four trials, and differentiated $C+2$ after 12 trials only. *Indicate a significant difference with response to conditioned odor. Data are available in Extended Data Figure 3-1.

Table 5. Summary of statistics for memory specificity experiment

\begin{tabular}{|c|c|c|c|}
\hline Repeated-measures ANOVA & Perceptually similar odor ${ }^{*} \mathrm{C}$ versus $\mathrm{C}+1$ & Perceptually less similar odor* $\mathrm{C}$ versus $\mathrm{C}+2$ & Unrelated odor ${ }^{*} \mathrm{C}$ versus $\mathrm{X}$ \\
\hline \multirow{5}{*}{$\begin{array}{l}F_{\text {odor }(3,29)}=14.063 ; p<0.0001 ; \\
\quad F_{\text {odor } * \text { drug } * \# \text { ttrials }(3,58)}=3.023 ; p=0.046\end{array}$} & Saline: & Saline: & Saline: \\
\hline & 4 trials: $p=0.139$ & 4 trials: $p=0.015$ & 4 trials: $p=0.036$ \\
\hline & 12 trials: 0.008 & 12 trials: 0.001 & 12 trials: 0.016 \\
\hline & Phentolamine: & Phentolamine: & Phentolamine: \\
\hline & 4 trials: $p=0.467$ & 4 trials: $p=0.238$ & 4 trials: $p=0.0 .001$ \\
\hline
\end{tabular}

'Significant decrease of digging during unrewarded trials indicates discrimination between $($ and novel odor (with Wilks' $\lambda$ ).

Escanilla, 2019) to which we added a behavioral readout ( $R N)$. We have systematically analyzed the cellular effects of NE in the OB before; here we present a proof of concept model for the prediction that the presence of $\mathrm{NE}$, via $\alpha 1$ receptors, modulates bulbar dynamics and, with it, plasticity, mediating stronger, longer-lasting, and more specific odor-reward associations. Our simplified model (Fig. 4A) implements NE modulation as measured in brain slice experiments (Nai et al., 2009, 2010; Linster et al., 2011; Linster, 2019) and in vivo (Manella et al., 2017), and determined computationally (Escanilla et al., 2010; Linster et al., 2011; de Almeida et al., 2015). Briefly, NE inputs to the OB model acting on $\alpha 1$ receptors enhanced MC excitability and GC spontaneous activity levels, resulting in stronger MC-GC interactions and more pronounced MC spike synchronization (Fig. 4B; quantified in Escanilla et al., 2010; de Almeida et al., 2015). When odor-reward association learning is simulated, synaptic weights between $\mathrm{OB}$ mitral cells and the $\mathrm{RN}$ increase in an activity-dependent manner. During learning, the RN is activated by a simulated reward signal, and the $\mathrm{OB}$ by the conditioned odor. Figure $4 C$ shows the evolution of the maximal synaptic weight in the model during acquisition (conditioned odor plus reward; TB1-TB4) and during the $24 \mathrm{~h}$ postacquisition time: when NE is simulated (compared with control mice), weights increase faster and to a higher level than when $\mathrm{NE}$ is not simulated ( $\mathrm{NpHR}$ mice). The maximal synaptic weights acquired with $\mathrm{NE}$ in the OB after two trial blocks (10 training trials) in the model are the same than those acquired after four trial blocks (20 training trials) without NE. Synaptic weights between MCs and RN increase faster when NE is implemented because MC spikes are more synchronous, drive the $\mathrm{RN}$, and the plasticity rule better. After acquisition, model parameters are set to No NE, and synaptic weights slowly decline back to baseline. As can be seen in the graph in Figure $4 C$ after a $2 \mathrm{~h}$ simulated decay time, both sets of weights are above baseline. However, after a $24 \mathrm{~h}$ simulated delay, weights acquired without NE modulation are not different from baseline-forgetting is complete-whereas weights acquired with NE modulation are higher than baseline. $\mathrm{RN}$ responses to the conditioned odor increase during acquisition in response to increasing synaptic weights and plateaus after two trial blocks for both NE and No NE simulations, showing that with the parameters chosen here, no strong effect of missing NE during acquisition is observed in $\mathrm{RN}$. RN responses continue to plateau during forgetting in the NE simulations, but not No NE simulations, and after $24 \mathrm{~h}$ of simulated forgetting time, the RN response is above baseline when acquired with $\mathrm{NE}$, but not when acquired without NE. These simulations show that in principle a simple effect on dynamics and synchrony in the $\mathrm{OB}$ can have no obvious acute effects but lead to substantial long-term effects in the next layers. Obviously, we could choose parameters to have many different outcomes and our model of $\mathrm{RN}$ and forgetting are simplified; however, this is a parsimonious proof of concept showing how local and temporary changes in neural dynamics can have multiple profound long-term effects.

We tested memory odor specificity in the model by presenting odors not used during acquisition, which differed in similarity with the conditioned odor $(\mathrm{C}+1 ; 78 \%$ overlap in OSN activation with $\mathrm{C}, \mathrm{C}+2 ; 34 \%$ overlap in OSN activation and $\mathrm{X}$; -0.42 overlap in OSN activation) and computing the RN response to these novel odors at different time points of the simulation (pretraining; after 1, 2, 3, or four training blocks; and post-training; Fig. 5A). The graph in Figure 5A shows the relative response magnitude of $\mathrm{RN}$ to novel odors with respect 


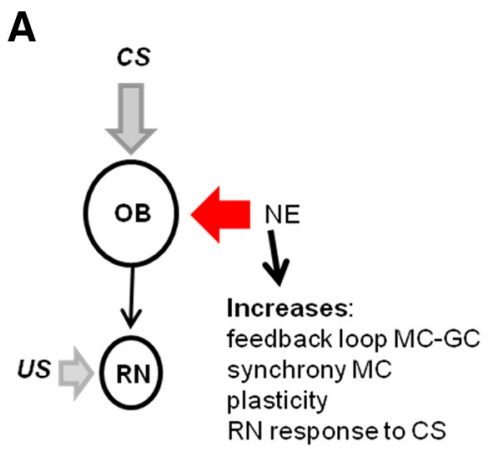

C

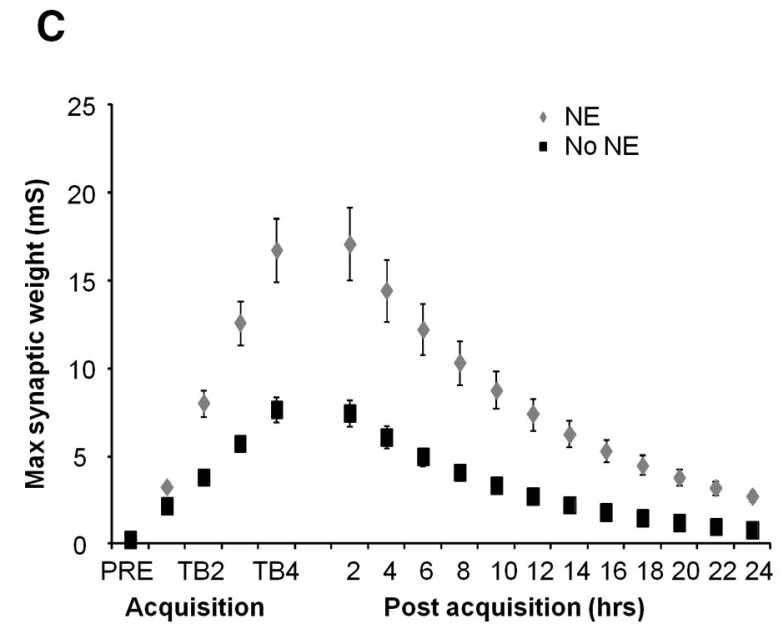

$\mathbf{B}_{\mathbf{i}}$

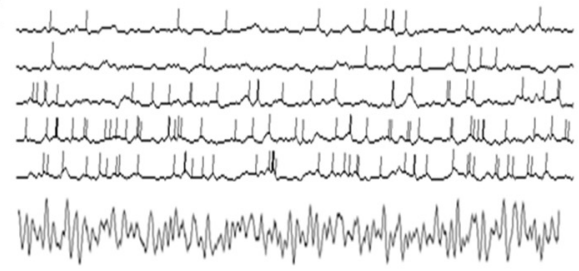

$\mathbf{B}_{\mathrm{ii}}$

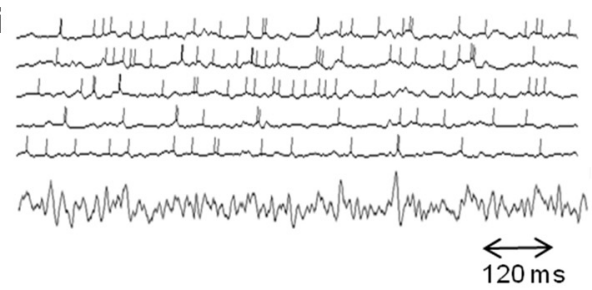

D

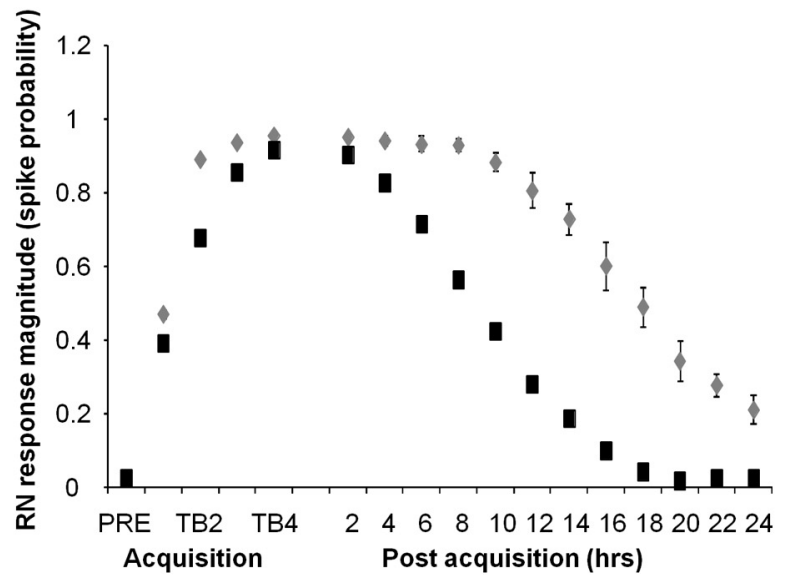

Figure 4. Computational modeling of bulbar NE effects on learning. $\boldsymbol{A}$, Schematic illustration of the model structure. Olfactory stimuli are sent to OB network via activation of simulated olfactory sensory neurons. The $O B$ network also receives NE modulatory inputs (see Materials and Methods). MCs make plastic excitatory synapses with an RN, which also receives input when a reward (US) is paired with an odor. $\boldsymbol{B}_{i}, \boldsymbol{B}_{i i}$, Neural activity and field potentials in the model with $\left(\boldsymbol{B}_{i}\right)$ and without $\left(\boldsymbol{B}_{i i}\right)$ NE modulation. The traces show action potentials and voltage fluctuations of representative $O B$ neurons in the model; the bottom trace shows the simulated field potential. Note that synchrony among spikes and field potential dynamics are decreased when NE modulation is impaired in the model. C, Changes in the maximal synaptic weights between MCs and RN. The graph shows the strength of synaptic weights (in mS) as a function of trial block during acquisition, and hours elapsed during forgetting (postacquisition in hours) for simulations with and without NE modulation. Note that when NE is omitted during acquisition, synaptic weights increase less and decreases to initial values by $18 \mathrm{~h}$, leading to nonrecall at the $24 \mathrm{~h}$ time point (compare with $\boldsymbol{D}$ ). $\boldsymbol{D}$, Response of RN (spike probability) to OB stimulation with the conditioned odor during acquisition and forgetting. RN response magnitude was measured after every trial block during acquisition and after every simulated hour during postacquisition (without US). Note that when NE modulation is omitted during acquisition, RN responses increase to the same asymptotic value, however, responses decrease more rapidly postacquisition, and by $18 \mathrm{~h}$ postacquisition RN responses are as low as baseline. Data are available in Extended Data Figure 4-1.

to the C. Pretraining, synaptic weights are at baseline and RN responds to all odor similarly (Fig. $5 B$ ). As training increases, RN responses become more specific: when trained with NE, $\mathrm{RN}$ response to all novel odors is much lower than the conditioned odor response after as few as two trial blocks (Fig. 5Ai). In contrast, the specificity of the response decreases more slowly when acquired without NE (Fig. 5Aii), with the response to $\mathrm{C}+1$ being significantly from $\mathrm{C}$ different after four trial blocks only. Overall, these results are similar to behavioral results showing that specificity increases with training and that this increase can be sped up by the presence of NE during learning. Note that these results are from the same simulations discussed above using the same parameters. Learning was simply halted after every training block and odors $\mathrm{C}, \mathrm{C}+1, \mathrm{C}+2$, and $\mathrm{X}$ presented to the network and the $\mathrm{RN}$ response computed. The evolution of specificity is clear when we observe how the distribution of synaptic weights to RN changes with learning (Fig. $5 \mathrm{Bi}, \mathrm{Bii}$ ). In each case, weight distribution is flat and random before learning. We are depicting a subset of weights organized to be centered at the most responsive glomerulus (to conditioned odor) with less responsive glomeruli flanking on each side. This depiction is for visualization purposes only, there is no such spatial organization in the model. After two training blocks, the distribution of synaptic weights is relatively flat for the No NE case and steeper for the NE case. Training with No $\mathrm{NE}$ after four trial blocks results in a similar weight distribution to training with $\mathrm{NE}$ after two trial blocks, mirroring the results from Figure 3. These results show that as synaptic weights increase, their distribution is rendered more narrow, resulting in more specific recall relative to the conditioned odor. When NE is not simulated, this process is slowed down. This is a direct result of mitral cell action potentials being more synchronous when $\mathrm{NE}$ is simulated as shown in Figure 5, Bi and Bii.

Overall, our simulations show that a simple network effect resulting in increased synchronization and higher signal-to-noise ratio during learning can have multiple long-term effects on odor-reward association. We created a very simplified model implementing cellular effects of NE meant to provide proof of concept rather than a detailed model of how odor-reward associations would happen. 
$\mathbf{A}_{\mathbf{i}}$

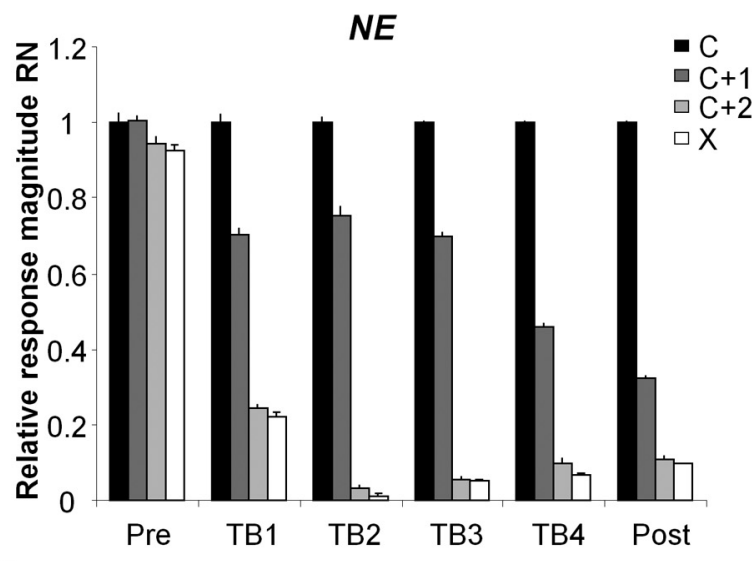

$A_{i i}$

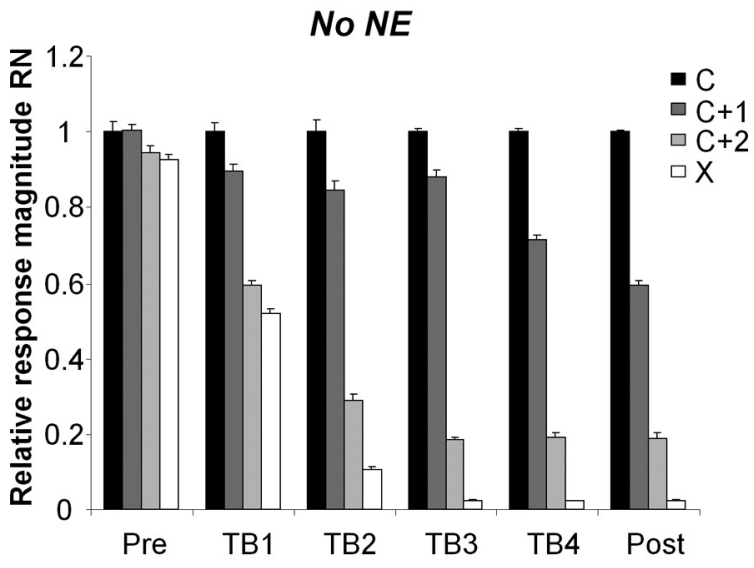

$B_{i}$

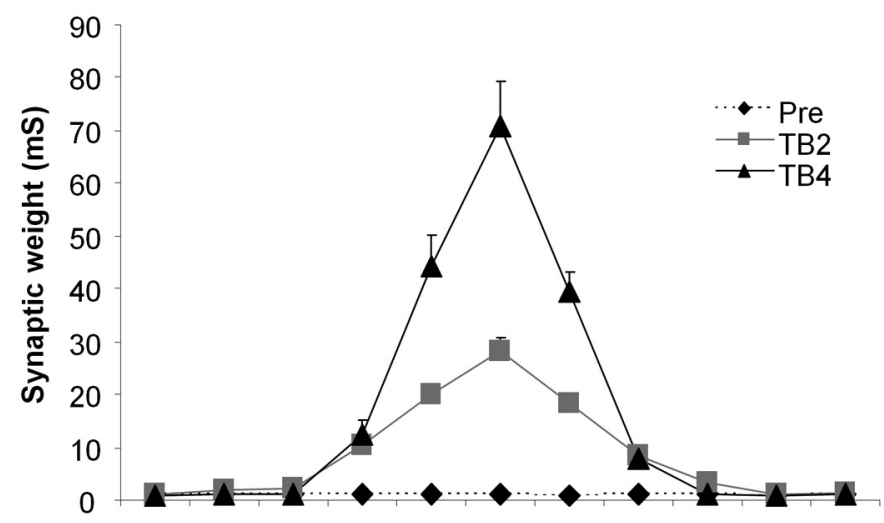

$B_{i i}$

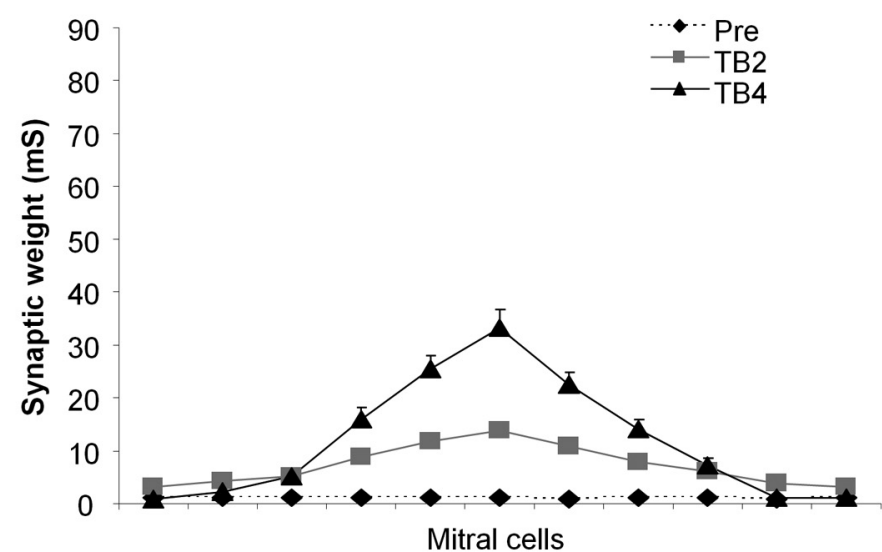

Figure 5. Odor specificity in the mode. $A_{i}, A_{i j}$ RN response magnitude over the course of training with $\left(A_{i}\right)$ and without $\left(A_{i j}\right)$ NE. The graphs show the ratio of RN response magnitude to novel odors $C+1, C+2, X)$ compared with the $C$ before training (Pre) and after 1, 2, 3, or 4 trial blocks. Note that specificity, indicated as responses to novel odors being lower than those to conditioned odor always increases with trial blocks, but this effect is more pronounced when NE modulation during training is simulated. RN responses are tested after each trial block in the absence of reward inputs. $\boldsymbol{B}_{i}, \boldsymbol{B}_{i i}$ Synaptic weight changes as a function of learning and NE inputs in the model. The graphs show synaptic weights normalized to the average initial weight

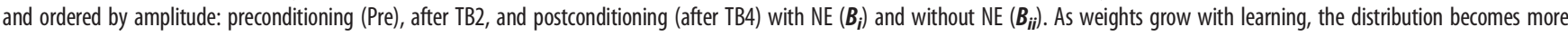
narrow and specific to the conditioned odor because of competition between synapses in the learning rule. Weight distributions are more narrow when acquisition is done in the presence of NE. Data are available in Extended Data Figure 5-1.

\section{Discussion}

Our experimental results show that the stability of an olfactory memory, measured by its perseverance, duration, and specificity, is decreased when NE release and activity is disturbed in the OB during acquisition. A computational model incorporating known cellular and network effects of NE in the OB (for review, see Linster and Escanilla, 2019) suggests that NE modulation of OB dynamics are mediating these effects. Interestingly we do not observe acute effects of lacking NE activity during learning, but see significant effects of this temporary manipulation long after the manipulation has stopped, which can underlie observations with respect to NE and stress in the OB (Manella et al., 2013) or $\mathrm{NE}$ and integration of adult-born neurons into the network (Moreno et al., 2012). We show that when NE is present in the OB during acquisition of an odor-reward association, synaptic weights mediating this association grow rapidly and specifically to the odor used for conditioning. At the end of acquisition, a strong and odor-specific association has been created because of strong synaptic plasticity in response to highly synchronous neural activity. This strong association is more difficult to reverse, takes longer to extinguish, and is more specific to the conditioned odor than an association acquired with $\mathrm{NE}$ activity in the olfactory decreased. NE has been shown to have a variety of effects on odor processing in the olfactory bulb, such as modulating odor detection thresholds (Escanilla et al., 2010, 2012; Linster and Escanilla, 2019), changing odor discrimination learning (Doucette et al., 2007; Mandairon et al., 2008), modulating habituation to an odor (Guérin et al., 2008; Manella et al., 2013), and affecting neural activity in response to an odor on a long timescale (Shea et al., 2008). With one exception (Shea et al., 2008), these effects have been measured when NE processes were actively manipulated in the OB. Here, we take advantage of optical techniques to manipulate NE release in the $\mathrm{OB}$ during acquisition only. Overall, our behavioral manipulations show that more learning leads to longer and more specific odor memories and that the presence of NE can speed up this process: less learning is needed for similar degrees of stability when NE is present.

Studies in hippocampus have shown that stimulation of LC fibers can result in release of DA as well as NE (Kempadoo et al., 2016; Takeuchi et al., 2016). Our optogenetic inhibition of release from LC fibers can thus result in a decrease of dopaminergic modulation in addition to the expected decrease in NE modulation. This is in contrast to the classic belief that DA is strictly internal to the OB (McLean and Shipley, 1988; Shipley and Ennis, 
1996). Dopamine receptors are known to be predominantly located in the input layer of the $\mathrm{OB}$ and are known to be regulated by overall sensory activity (Brunjes et al., 1985), adding to olfactory bulb homeostasis. Behaviorally, we and others showed that the activation of $\mathrm{D}_{2}$ receptors locally in the $\mathrm{OB}$ can decrease odor detection and discrimination at low odor concentrations. Electrophysiological results show a predominant effect on glomerular layer computations with $\mathrm{D}_{1}$ receptor activation increasing excitation in that layer (Liu, 2020) and $\mathrm{D}_{2}$ receptor activation decreasing odor responses. It is therefore possible that limiting dopaminergic release from LC fibers could contribute to our observations, with the caveat that LC projections terminate predominantly in the deeper layers of $\mathrm{OB}$ and are less present in the glomerular layer where DA would be most effective. Behavioral results show that locally activating $\mathrm{DA}$ receptors in the $\mathrm{OB}$ decreases odor detection Escanilla et al., 2009, whereas local activation of NE receptors increases odor detection. Given that pharmacological blockade of NE receptors replicate the effects of LC fiber inhibition, we are confident that our observations can be largely attributed to the effects of reducing NE with a possible small contribution of DA.

Stress during learning can affect memory duration and stability. For example, when rats were acutely stressed during a simple odor-encoding task, memory for the encoded odor was enhanced (Manella et al., 2013). Interestingly, this enhancement could be mimicked by direct infusion of NE into the first sensory processing network, the $\mathrm{OB}$, and the effect of stress was blocked by application of NE antagonists during the stress phase (Manella et al., 2013). Reversal learning, commonly used to study cognitive flexibility, has been shown to be facilitated by some types of long-term stress (Dong et al., 2013; Thai et al., 2013), suggesting a facilitatory role of NE, as we observe in the present experiments (Zitnik et al., 2016). Directly enhancing LC neural activity can also facilitate reversal learning that is dependent on activity levels (Snyder et al., 2012).

Here we show the long-term effects of a temporary decrease of NE in an early sensory structure influencing or driving downstream plasticity processes. While it is well known that NE modulates plasticity in many ways, in our experiment NE is not manipulated in those networks assumed to undergo plasticity. Rather, temporary changes in dynamics during acquisition create long-term effects downstream. In the computational model, rapid within bulbar plasticity, assumed to be modulated by NE, is not included. Activity-dependent plasticity between mitral and granule cells, for example, would further modulate bulbar dynamics and be additive to the mechanisms proposed here. However, such direct plasticity could be expected to speed up acquisition, which is not a phenomenon that we observe behaviorally in our tasks (possibly because of ceiling effects). We here present the most parsimonious mechanism, without claiming that many processes interact with each other and many of these can be modulated by NE. We simply show proof of concept for the idea that local and temporary changes in a sensory network can have long-lasting effects expressed downstream. Once changes in response to odorants have been established in postbulbar processes ( $\mathrm{RN}$ in our simplified model), manipulating bulbar dynamics has less of an effect because dynamics, while crucial to plasticity processes, have less of an effect on readout, which can be thought of as a more rate-dependent process.

A previous study showed that NE activity in the amygdala can modulate the stability of fear memories in networks receiving inputs from the amygdala (Haubrich et al., 2020); these results are in good agreement with our present experiments. The present results go beyond what was previously shown to be a role for NE modulation in the $\mathrm{OB}$ with respect to signal-to noise modulation and odor discrimination (for review, see Linster and Escanilla, 2019) by showing that these acute processes can have long-lasting effects beyond the time when NE modulates the OB network. Thus, changes in network dynamics as early as the $\mathrm{OB}$ can directly influence odor processing and plasticity in higherorder structures leading to more stable memory consolidation. NE-mediated effects of acute stress can outlast the period of stress; here we show that these effects do not always rely on direct modulation of plasticity in the network in question. Our model relies on known and previously modeled cellular effects of NE to create predictions about the long-term behavioral effects we have observed here. As shown before, different aspects of olfactory memory such as duration and specificity covary (Freedman et al., 2013; Hackett et al., 2015) and can be ascribed to a common mechanism rather than evolving independently.

\section{References}

Brunjes PC, Smith-Crafts LK, McCarty R (1985) Unilateral odor deprivation: effects on the development of olfactory bulb catecholamines and behavior. Brain Res 354:1-6.

Chaudhury D, Escanilla O, Linster C (2009) Bulbar acetylcholine enhances neural and perceptual odor discrimination. J Neurosci 29:52-60.

Cho C, Linster C (2020) Experience enhances certainty about olfactory stimuli under bulbar cholinergic control. Learn Mem 27:414-417.

Cleland TA, Chen SY, Hozer KW, Ukatu HN, Wong KJ, Zheng F (2011) Sequential mechanisms underlying concentration invariance in biological olfaction. Front Neuroeng 4:21.

Cleland TA, Narla VA (2003) Intensity modulation of olfactory acuity. Behav Neurosci 117:1434-1440.

Cleland TA, Morse A, Yue EL, Linster C (2002) Behavioral models of odor similarity. Behav Neurosci 116:222-231.

Cleland TA, Narla VA, Boudadi K (2009) Multiple learning parameters differentially regulate olfactory generalization. Behav Neurosci 123:26-35.

de Almeida L, Reiner SJ, Ennis M, Linster C (2015) Computational modeling suggests distinct, location-specific function of norepinephrine in olfactory bulb and piriform cortex. Front Comput Neurosci 9:73.

Devore S, Linster C (2012) Noradrenergic and cholinergic modulation of olfactory bulb sensory processing. Front Behav Neurosci 6:52.

Devore S, de Almeida L, Linster C (2014) Distinct roles of bulbar muscarinic and nicotinic receptors in olfactory discrimination learning. J Neurosci 34:11244-11260.

Dong Z, Bai Y, Wu X, Li H, Gong B, Howland JG, Huang Y, He W, Li T, Wang YT (2013) Hippocampal long-term depression mediates spatial reversal learning in the Morris water maze. Neuropharmacology 64:65-73.

Doucette W, Milder J, Restrepo D (2007) Adrenergic modulation of olfactory bulb circuitry affects odor discrimination. Learn Mem 14:539-547.

Escanilla O, Mandairon N, Linster C (2008) Odor-reward learning and enrichment have similar effects on odor perception. Physiol Behav 94:621-626.

Escanilla O, Yuhas C, Marzan D, Linster C (2009) Dopaminergic modulation of olfactory bulb processing affects odor discrimination learning in rats. Behav Neurosci 123:828-833.

Escanilla O, Arrellanos A, Karnow A, Ennis M, Linster C (2010) Noradrenergic modulation of behavioral odor detection and discrimination thresholds in the olfactory bulb. Eur J Neurosci 32:458-468.

Escanilla O, Alperin S, Youssef M, Ennis M, Linster C (2012) Noradrenergic but not cholinergic modulation of olfactory bulb during processing of near threshold concentration stimuli. Behav Neurosci 126:720-728.

Freedman KG, Radhakrishna S, Escanilla O, Linster C (2013) Duration and specificity of olfactory nonassociative memory. Chem Senses 38:369-375.

Gentry RN, Schuweiler DR, Roesch MR (2019) Dopamine signals related to appetitive and aversive events in paradigms that manipulate reward and avoidability. Brain Res 1713:80-90.

Gradinaru V, Zhang F, Ramakrishnan C, Mattis J, Prakash R, Diester I, Goshen I, Thompson KR, Deisseroth K (2010) Molecular and cellular approaches for diversifying and extending optogenetics. Cell 141:154165. 
Guérin D, Peace ST, Didier A, Linster C, Cleland TA (2008) Noradrenergic neuromodulation in the olfactory bulb modulates odor habituation and spontaneous discrimination. Behav Neurosci 122:816-826.

Hackett C, Choi C, O'Brien B, Shin P, Linster C (2015) Odor memory and discrimination covary as a function of delay between encoding and recall in rats. Chem Senses 40:315-323.

Haubrich J, Bernabo M, Nader K (2020) Noradrenergic projections from the locus coeruleus to the amygdala constrain fear memory reconsolidation. Elife 9:e57010.

Kempadoo KA, Mosharov EV, Choi SJ, Sulzer D, Kandel ER (2016) Dopamine release from the locus coeruleus to the dorsal hippocampus promotes spatial learning and memory. Proc Natl Acad Sci U S A 113:14835-14840.

Kermen F, Chakirian A, Sezille C, Joussain P, Le Goff G, Ziessel A, Chastrette M, Mandairon N, Didier A, Rouby C, Bensafi M (2011) Molecular complexity determines the number of olfactory notes and the pleasantness of smells. Sci Rep 1:206.

Kermen F, Midroit M, Kuczewski N, Forest J, Thévenet M, Sacquet J, Benetollo C, Richard M, Didier A, Mandairon N (2016) Topographical representation of odor hedonics in the olfactory bulb. Nat Neurosci 19:876-878.

Linster C (2019) Cellular and network processes of noradrenergic modulation in the olfactory system. Brain Res 1709:28-32.

Linster C, Escanilla O (2019) Noradrenergic effects on olfactory perception and learning. Brain Res 1709:33-38.

Linster C, Hasselmo ME (1999) Behavioral responses to aliphatic aldehydes can be predicted from known electrophysiological responses of mitral cells in the olfactory bulb. Physiol Behav 66:497-502.

Linster C, Kelsch W (2019) A Computational Model of Oxytocin Modulation of Olfactory Recognition Memory. eNeuro 6.

Linster C, Nai Q, Ennis M (2011) Nonlinear effects of noradrenergic modulation of olfactory bulb function in adult rodents. J Neurophysiol 105:1432-1443.

Liu S (2020) Dopaminergic modulation of glomerular circuits in the mouse olfactory bulb. Front Cell Neurosci 14:172.

Mandairon N, Ferretti CJ, Stack CM, Rubin DB, Cleland TA, Linster C (2006) Cholinergic modulation in the olfactory bulb influences spontaneous olfactory discrimination in adult rats. Eur J Neurosci 24:3234-3244.

Mandairon N, Peace S, Karnow A, Kim J, Ennis M, Linster C (2008) Noradrenergic modulation in the olfactory bulb influences spontaneous and reward-motivated discrimination, but not the formation of habituation memory. Eur J Neurosci 27:1210-1219.

Mandairon N, Sultan S, Rey N, Kermen F, Moreno M, Busto G, Farget V, Messaoudi B, Thevenet M, Didier A (2009) A computer-assisted odorized hole-board for testing olfactory perception in mice. J Neurosci Methods 180:296-303.

Mandairon N, Kuczewski N, Kermen F, Forest J, Midroit M, Richard M, Thevenet M, Sacquet J, Linster C, Didier A (2018) Opposite regulation of inhibition by adult-born granule cells during implicit versus explicit olfactory learning. Elife 7:e34976.

Manella LC, Alperin S, Linster C (2013) Stressors impair odor recognition memory via an olfactory bulb-dependent noradrenergic mechanism. Front Integr Neurosci 7:97.

Manella LC, Petersen N, Linster C (2017) Stimulation of the locus ceruleus modulates signal-to-noise ratio in the olfactory bulb. J Neurosci 37:11605-11615.

McBurney-Lin J, Lu J, Zuo Y, Yang H (2019) Locus coeruleus-norepinephrine modulation of sensory processing and perception: a focused review. Neurosci Biobehav Rev 105:190-199.
McIntyre AB, Cleland TA (2016) Biophysical constraints on lateral inhibition in the olfactory bulb. J Neurophysiol 115:2937-2949.

McLean JH, Shipley MT (1988) Postmitotic, postmigrational expression of tyrosine hydroxylase in olfactory bulb dopaminergic neurons. J Neurosci 8:3658-3669.

Moreno MM, Bath K, Kuczewski N, Sacquet J, Didier A, Mandairon N (2012) Action of the noradrenergic system on adult-born cells is required for olfactory learning in mice. J Neurosci 32:3748-3758.

Nai Q, Dong HW, Hayar A, Linster C, Ennis M (2009) Noradrenergic regulation of GABAergic inhibition of main olfactory bulb mitral cells varies as a function of concentration and receptor subtype. J Neurophysiol 101:2472-2484.

Nai Q, Dong HW, Linster C, Ennis M (2010) Activation of alpha1 and alpha2 noradrenergic receptors exert opposing effects on excitability of main olfactory bulb granule cells. Neuroscience 169:882-892.

Parikh V, Sarter M (2008) Cholinergic mediation of attention: contributions of phasic and tonic increases in prefrontal cholinergic activity. Ann N Y Acad Sci 1129:225-235.

Raimondo JV, Kay L, Ellender TJ, Akerman CJ (2012) Optogenetic silencing strategies differ in their effects on inhibitory synaptic transmission. Nat Neurosci 15:1102-1104.

Sarter M, Gehring WJ, Kozak R (2006) More attention must be paid: the neurobiology of attentional effort. Brain Res Rev 51:145-160

Shea SD, Katz LC, Mooney R (2008) Noradrenergic induction of odor-specific neural habituation and olfactory memories. J Neurosci 28:1071110719 .

Shipley MT, Ennis M (1996) Functional organization of olfactory system. J Neurobiol 30:123-176.

Snyder K, Wang WW, Han R, McFadden K, Valentino RJ (2012) Corticotropin-releasing factor in the norepinephrine nucleus, locus coeruleus, facilitates behavioral flexibility. Neuropsychopharmacology $37: 520-530$

Spellman T, Rigotti M, Ahmari SE, Fusi S, Gogos JA, Gordon JA (2015) Hippocampal-prefrontal input supports spatial encoding in working memory. Nature 522:309-314.

Stuber GD, Sparta DR, Stamatakis AM, van Leeuwen WA, Hardjoprajitno JE, Cho S, Tye KM, Kempadoo KA, Zhang F, Deisseroth K, Bonci A. (2011) Excitatory transmission from the amygdala to nucleus accumbens facilitates reward seeking. Nature 475:377-380.

Takeuchi T, Duszkiewicz AJ, Sonneborn A, Spooner PA, Yamasaki M, Watanabe M, Smith CC, Fernández G, Deisseroth K, Greene RW, Morris RG (2016) Locus coeruleus and dopaminergic consolidation of everyday memory. Nature 537:357-362.

Thai CA, Zhang Y, Howland JG (2013) Effects of acute restraint stress on setshifting and reversal learning in male rats. Cogn Affect Behav Neurosci 13:164-173.

Tong MT, Kim TP, Cleland TA (2018) Kinase activity in the olfactory bulb is required for odor memory consolidation. Learn Mem 25:198-205.

Tye KM, Prakash R, Kim SY, Fenno LE, Grosenick L, Zarabi H, Thompson KR, Gradinaru V, Ramakrishnan C, Deisseroth K (2011) Amygdala circuitry mediating reversible and bidirectional control of anxiety. Nature 471:358-362.

Zitnik GA, Curtis AL, Wood SK, Arner J, Valentino RJ (2016) Adolescent social stress produces an enduring activation of the rat locus coeruleus and alters its coherence with the prefrontal cortex. Neuropsychopharmacology 41:1376-1385. 